\title{
Eğitsel Oyuncak ve Eğitsel Oyun İçerikli Araştırmalardaki Ĕgilimler: İçerik Analizi
}

\author{
Seraceddin Levent Zorluoğlu*, Burcu Çakır Elbir**
}

Makale Geliş Tarihi: 02/05/2018

Makale Kabul Tarihi: 09/11/2018

DOI: $10.35675 /$ befdergi.420203

$\ddot{O} z$

Bu çalışmanın amacı, Türkiye'de eğitsel oyuncak ve eğitsel oyunların araştırmasını yapan, eğitsel oyuncak ve oyunların türlerini belirleyen ve eğitim-öğretim sürecindeki etkililiğini test eden tezlerin içerik analizini yaparak araştırma bulgularını farklı açılardan ortaya koymaktır. Bu amaç doğrultusunda YÖK Ulusal Tez Merkezinde 1997-2017 yılları aralı̆̆ında basılan, 'oyun', 'oyuncak' ve 'eğitsel oyun' anahtar kavramlarından herhangi birini ya da birkaçın kapsayan 112 tez belirlenmiştir. Bu tezler, araştırmactlar tarafindan revize edilen 'Tez Sinıflama Formu' kullanılarak betimsel türde içerik analize tabi tutulmuştur. Tezlerde veri toplama aracı olarak en çok başarı testi, kişisel bilgi formu ve çeşitli ölçek türlerinin kullanıldı̆̆ $\mathrm{l}$ belirlenmiştir. Verilerin analizi için ise nitel analiz yöntemlerinden içerik analizinin ön planda olduğu, nicel analiz yöntemlerinden ise t-testi, non-parametrik testler ile ANOVA/ANCOVA testlerini daha çok tercih ettikleri ortaya çıkmıştır.

Anahtar Kelimeler: Oyun, oyuncak, ĕgitsel oyun

\section{Trends of Studies Published in The field of Educational Toys and Games Research: Content Analysis}

\begin{abstract}
The aim of this study is to analyze the educational toys and educational games of thesises published by researchers in Turkey in terms of content and methodological aspects and to reveal the findings of research from different angles For this aim, the thesises published in YÖK National Thesis Center during the years 1997-2017 were reviewed in accordance with criteria of inclusion of the research (game-toy-educational play) and a total of 112 theses were included in this study. In the current study, success test, personal information form and various scale types were mostly used for data collection. For the analysis of data it was found that descriptive analysis were made more commonly and ANOVA/ANCOVA and t-test analysis were also used in the studies intensively.
\end{abstract}

Keywords: Game, toy, educational game

\footnotetext{
* Süleyman Demirel Üniversitesi, Eğitim Fakültesi, Matematik ve Fen Bilimleri Eğitimi Bölümü, Isparta, Türkiye, leventzorluoglu@ hotmail.com, ORCID: 0000-0002-8958-0579

** Süleyman Demirel Üniversitesi, Eğitim Fakültesi, Matematik ve Fen Bilimleri Eğitimi Bölümü, Isparta, Türkiye, burcu_cakir55@hotmail.com, ORCİD: 0000-0002-8564-5224
}

Kaynak Gösterme: Zorluoğlu, S.L. ve Çakır-Elbir, B. (2019). Eğitsel oyuncak ve eğitsel oyun içerikli araştırmalardaki eğilimler: İçerik analizi. Bayburt Eğitim Fakültesi Dergisi, 14(27), 1-22. https://doi.org/10.35675/befdergi.420203 


\section{Giriş}

İnsanlar sorgulayıcı, yargılayıcı, tartışmaya açık olma gibi bazı özellikleri sayesinde ilk çağlardan itibaren evreni ve yaşadığı çevreyi anlamaya, olaylar arasında nedensonuç ilişkileri kurarak sonuçlar elde etmeye çalışmaktadırlar. İnsanoğlunun yaşadığ 1 çevreyi anlama gayretleri yaşamımızın ayrılmaz parçası olan fen bilimlerini bir ürün olarak karşımıza çıkarmaktadır (Kaptan, 1999).

Günümüz bilgi çağında, insanların bilgiye verdikleri önem, var olan bilgilerden yararlanma ve daha fazla bilgiye ulaşma isteği gün geçtikçe artmaktadır. Bu önem ve isteğe cevap oluşturmaya çalışan fen bilimleri, eğitim-öğretim sürecinde ders olarak bireylerin karşısına çıkmaktadır. Fen bilimleri dersinde insanın doğası gereği araştırma ve sorgulamaya dayalı öğretim yöntemleri temel alınmakta, öğrencilerin aktif olduğu problem çözme, proje tasarlama ve argümantasyon gibi işbirliğine dayalı öğretim stratejilerine ağırlık verilmektedir (Milli Eğitim Bakanlığı [MEB], 2013). Bu öğretim stratejileri etkili bir fen öğretimi için gerekli görülmektedir. Etkili bir fen öğretimi ise sadece stratejiler ile değil fen bilimleri programlarında yer alan kazanımlar, kavramlar veya yaşamda yer alan durumlar ile ilişkisel olarak ortaya çıkarılmasıyla gerçekleşebilmektedir (Çoşkun, Akarsu ve Kariper, 2012; Hançer, 2007; Özkan, 2010). Bu nedenle ilköğretim çağındaki öğrencilerin her şeyden önce ruhsal ve sosyal yönden bir bütün olarak gelişimlerini tamamlamış bireyler olmaları, bütün alanlarda olduğu gibi fen bilimleri alanında da olumlu tutum geliştirmeleri, daha sonrada fen bilimleri ile ilgili temel becerileri kazanmaları sağlanmalıdır.

Çocukların eğitim-öğretim sürecine severek/isteyerek dâhil edilebilmesinde ve fen bilimleri ile ilgili temel becerileri kazanmalarında çeşitli yöntemler kullanılmaktadır. İlkokul ve ortaokul çağındaki çocuklar için öğretimde öğretmenlerin tercih edebileceği yöntemlerden biri oyun ve oyuncak ile öğretimdir (Altunay, 2004; Demir, 2012). Oyun ve oyuncaklar, çocukların ilk yaşlarından başlayarak gelişimlerini etkileyen ve her zaman ilgi duydukları önemli bir etkinliktir. Yapılan araştırmalar, bu oyun ve oyuncak olgularının eğitime uyarlanması ve eğitimde kullanılmasını kaçınılmaz bulup olumlu sonuçlar doğurduklarını belirtmektedir.

Piaget oyunu; "Oyun bir uyumdur. Oyun, çocuğa hiç kimsenin öğretemeyeceği konuları çocuğun kendi deneyimleriyle öğrenmesi yöntemidir." Şeklinde tanımlamaktadır (Yavuzer, 1984, s.199). Farklı çalışmalarda ise oyun, çocukların isteyerek yer aldığı, genellikle belirli bir amacı olan, bazılarının kurallara dayandığı, çok yönlü gelişime odaklanmış en etkin öğrenme süreci olarak ifade edilmektedir (Baykoç ve Dönmez, 1992; Varışoğlu, Şeref, Gedik ve Yılmaz, 2013; Vygotsky, 1986). Oyuncak ise gelişim evrelerinde çocuğun hareketlerinde bir düzen sağlayan, zihinsel-bedensel-psikososyal gelişimine olumlu katkıda bulunan, hayal gücü ile yaratıcılıklarını geliştiren, mantıksal düşünmeyi hızlandıran ve neden sonuç ilişkisi oluşturan tüm oyun malzemeleri olarak tanımlanmaktadır (Oktay, 2002; Razon, 1984). Bir çocuk, etrafinda bulunan her şeyi oyuncak olarak kullanıp onunla oyunlar kurabilmektedir. 
Tural (2005), öğretimin kazandırmayı planladığı amaçlara uygun olarak eğitimöğretim etkinliklerine hizmet edebilecek her oyun ve oyuncağın eğitim-öğretim sürecinde kullanılabileceğini savunmaktadır. Günümüz eğitim sisteminde de derslerde öğrenilen kavramların pekiştirilmesi, daha rahat bir ortamda tekrar edilmesinin sağlanması, öğrenme ve okul ortamının eğlenceli bir yer haline getirilmesi, ögrrencilerin derslere olan olumsuz önyarg1 ve tutumlarının olumlu hale getirilmesi amacıyla oyun ve oyuncaklara yer verilmektedir. Öğretimde kullanılan oyun ve oyuncaklarda dikkat edilmesi gereken tek nokta ise belli bir hedefe odaklanılarak verilmesi ya da belirli kazanımlar doğrultusunda kullanılıyor olmasıdır. Oyun ve oyuncak konunun kazanımlarıyla ne kadar ilişkili, öğrencilerin yaşınacinsiyetine ve gelişim özelliklerine ne kadar uygun ve ne kadar merak uyandırıcı ise o kadar etkili olarak kabul edilmektedir (Bilen, 2002; Dağbaşı, 2007).

Eğitimde uygulanmak üzere hazırlanmış olan oyun ve oyuncakların önemi kadar bunların eğitim-öğretim ortamına nasıl aktarıldığı ve ortamda nasıl kullanıldığı da oldukça önemlidir. Uygun ortam ve uygulanma koşulları sağlanmadığı takdirde oyun ve oyuncaklar çocuk için eğlendirici, öğretici ve geliştirici bir faktör olmaktan çıkıp can sıkıcı bir etkinlik hâline gelebilmektedir (Koçyiğit, Tuğluk ve Kök, 2007). Bu nedenle çocuklar için hedeflenen amaç ve başarıya ulaşılmasında oyunun kontrolü, yönetimi ve uygulanması noktasında öğretmenlere önemli görevler düşmektedir. Öğretmenler, öncelikle öğretim için dikkatli ve titiz bir hazırlık yapmalı, öğrencilerin farklı düzey ve yeteneklerine uyarlanabilecek esneklikte tercihlerde bulunmalı (Demirel, 1999), sonradan çıkabilecek gürültü, kargaşa ve disiplin problemlerini önlemek için oyuncakların nasıl kullanılması gerektiğini ve oyunların kurallarını açıkça öğrencilere ifade etmelidir (Altun, 2009; Kirazoğlu, 2000).

Derslerin öğretmenin rehber, öğrencinin ise aktif olduğu öğretim yöntemleri ile yürütülmesi, eğitsel oyuncak ve oyunlarla istenilen hedeflere daha kolay ulaşılması, eğitim kalitesinin yükseltilmesi ve bu konudaki uygulama ve araştırma çalışmalarının sürekliliğinin sağlanması için alanyazında bu konuda yapılan çalışmaların belirli tanımlama ölçütlerine uygun olacak şekilde analiz edilmesi ve bütünsel değerlendirmesinin yapılması oldukça önemlidir. Genel eğilimlerin belirlenerek irdelenen çalışmaların hangi konular etrafında yoğunlaştığını açığa çıkarmak ve bu alandaki eksiklikleri ortaya koymak çalışmanın temel amacıdır. Bu analiz ve değerlendirme sayesinde, eğitsel oyuncak ve oyunların eğitim sistemimize ne kadar yansıdığı hakkında kapsamlı bir fikir edinilmiş olup 20 yıllık dönemde nasıl bir yol izlediğinin ortaya koyulabileceği düşünülmektedir. Çalışma eğitsel oyuncak ve oyunların öğretim programında kullanılmasını faydalı bulan yeni ya da deneyimli araştırmacıların yapılmış olan çalışmalardan haberdar olmalarını sağlayarak gelecekte yapılacak olan çalışmalara yol gösterici niteliğinde olacaktır.

Çalışma kapsamında aşağıdaki sorulara yanıt aranmaya çalışılmıştır:

Lisansüstü tez çalışmalarının; 
1. Türe göre istatiksel dağılımı nasıl değişmiştir?

2. Yıla göre istatiksel dağılımı nasıl değişmiştir?

3. Üniversitelere göre dağılımı nasıldır?

4. Anabilim dallarına göre dağılımları nasıldır?

5. Örneklem/ çalışma gruplarının büyüklüğü nasıl değişmektedir?

6. Örneklem/ çalışma gruplarının düzeyi nasıl değişmektedir?

7. Sıklıkla kullandıkları değişkenler nelerdir?

8. Sıklıkla kullandıkları araştırma desenleri/yöntemleri nelerdir?

9. Sıklıkla kullandıkları veri toplama araçları hangileridir?

10. Sıklıkla kullandıkları veri analiz yöntemleri hangileridir?

\section{Yöntem}

Bu çalışmada, Türkiye'de yapılmış olan 'oyun', 'oyuncak' ve 'eğitsel oyun' anahtar kavramlarından herhangi birini ya da birkaçını içeren, eğitsel oyuncak ve eğitsel oyunların araştırmasını yapan, eğitsel oyuncak ve oyunların türlerini belirleyen ve eğitim-öğretim sürecinde eğitsel oyuncak/oyunların etkililiğini test eden bilimsel araştırma tezleri incelenmiştir. Bu amaçla doküman inceleme çalışması yapılmıştır. Araştırılacak bir konuyla ilgili, bilgi içeren yazılı materyallerin toplanarak analizinin yapılması olarak tanımlanan (Yıldırım ve Şimşek, 2005) doküman analizi, tespit edilen materyallerin sistematik bir şekilde taranarak incelenmesini kapsayan nitel bir çalışmadır (Ekiz, 2009; Yıldırım ve Şimşek, 2011). Doküman incelemek amacıyla içerik analizleri yapılmaktadır. İçerik analizleri kendi içinde meta-analiz, meta-sentez (tematik içerik analiz) ve betimsel içerik analiz olarak üç başlık altında irdelenmektedir. Bu çalışmada ulaşılabilen lisansüstü araştırma tezleri, tez sınıflama formunda belirlenen kriterlere uygun olarak analiz edilmiş ve bu alandaki genel eğilimleri saptayabilmek amacıyla içerik analizi çeşitlerinden betimsel içerik analizi çalışması yapılması uygun bulunmuştur. Betimsel türde içerik analizine, 'belirlenmiş bir konu hakkında yapılan çalışmaların taranarak saptanması', 'genel olarak eğilimlerinin belirlenmesi, araştırma sonrası elde edilen sonuçların tanımlayıcı olarak değerlendirilmesini kapsayan planlı çalışmalar bütünü' vb. gibi değişik tanımlamalar getirilmiştir (Çalık, Ünal, Coştu ve Karataş, 2008; Göktaş vd., 2012a; Gül ve Sözbilir, 2015; Selçuk, Palanc1, Kandemir ve Dündar, 2014; Sözbilir, Kutu ve Yaşar, 2012; Topsakal, Çalık ve Çavuş, 2012). Yani, betimsel türde içerik analiziyle, belirlenen konu ile ilgili alanyazında çalışma yapan ya da yapmayı planlayan araştırmacılara genel eğilimin nasıl olduğu açıklanmakta, araştırmaları için bir öngörü oluşturulmaktadır (Cohen ve Manion, 2001; Selçuk, Palanc1, Kandemir ve Dündar, 2014). 
Çalışma kapsamına dahil edilen tezler, YÖK Ulusal Tez Merkezinden ulaşılabilir olanlar ile sınırlıdır. Araştırma kapsamında sadece Türkçe olarak yazılmış olan tezler kullanılmıştır. YÖK Ulusal Tez Merkezinde 13 Aralık 2017 tarihinden başlanarak 'oyun', 'oyuncak' ve 'eğitsel oyun' anahtar kavramlarına ilişkin olarak yapılan taramada 1997-2017 yıllarına ait toplam 150 adet teze ulaşılmıştır. Ulaşılan 150 tezden 112'si (\%75) bu araştırmada içerik analizine tabi tutulmuş, 38'i ise (\%25) erişim sorunu yaşanması sebebiyle araştırma kapsamına dâhil edilememiştir.

Elde edilen lisansüstü tez çalışmalarının incelenmesinde Göktaş vd. (2012b) tarafından geliştirilen Yayın Sınıflama Formu rehber olarak alınıp araştırmacılar tarafından revize edilerek kullanılmıştır. Veri toplama aracında yer almakta olan inceleme kategorileri, araştırmacılar tarafından ilgili alan yazın taranarak hazırlanmıştır. Görüşlerine başvurulan içerik analizinde uzmanlaşmış ve oyun/oyuncak konusunda çalışmaları olan iki uzmandan, analiz formunda yer alan maddeleri amaca uygunluk bakımından incelemeleri istenmiş ve uzmanlara formdaki maddelerden gerekiyorsa ekleme-çıkarma yapabilecekleri belirtilmiştir. Araştırmacılar uzman görüşlerini dikkate alarak analiz formuna son şekli vermiş kullanıma hazır hale getirmişlerdir.

Tezlerin sınıflandırılma sürecinde araştırmacılar birlikte çalışmıştırlar. Erişilen tezler tek tek incelenip araştırma konularına göre ön tasnif yapıldıktan sonra içerik analizine tabi tutulmuştur. Tez sınıflama formu kullanılarak tezlerin türü, yapıldığı üniversite, anabilim dalı, yapılan araştırmaların yıllara göre dağılımı, çalışma gruplarının düzeyi ve büyüklükleri, kullanılan değişkenler, araştırma yöntemleri, veri analiz türleri ve veri toplamak için kullanılan araçlar olmak üzere on ana tema belirlenmiştir. Temalar üzerinden ulaşılmış olan bulgular yüzde-frekans tabloları ve grafik kullanılarak görselleştirilmiş ve yorumlanmıştır.

\section{Bulgular ve Yorum}

Bu çalışmada, YÖK Ulusal Tez Merkezi veri tabanı kullanılarak yapılan alanyazın taraması sonucu 1997-2017 yılları aralığında Türkiye'de eğitsel oyuncak ve eğitsel oyun içerikli araştırma yapan 112 çalışmanın içerik analizi yapılmıştır. Yapılan içerik analiziyle ulaşılan tüm bulgular ise araştırma sorularına paralel olarak sırasıyla aşağıda sunulmuştur.

\section{Lisansüstü Tez Çalışmalarının Türleri Açısından Dağılımı}

İçerik analizi yapılan 112 lisansüstü tez çalışmasının türleri açısından dağılımı Şekil 1 'de gösterilmektedir. 


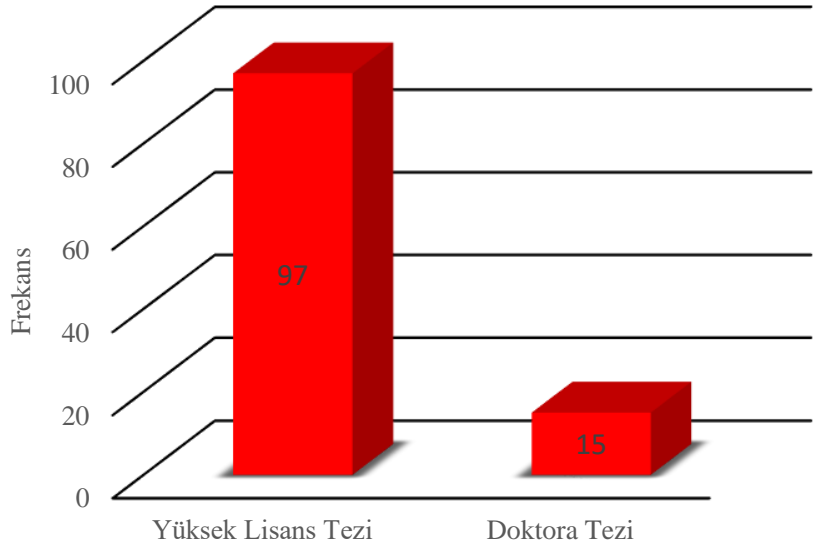

Şekil 1. Lisansüstü tez çalışmalarının türleri

Şekil 1 incelendiğinde eğitsel oyuncak ve eğitsel oyun ile ilgili 112 tezden 97'sinin (\%86.6) yüksek lisans tezi, 15'inin (\%13.4) ise doktora tezi olduğu görülmektedir. 1997-2017 yılları arasında yazılmış olan yüksek lisans tezi sayısının doktora tezi sayısının 4 katından fazla olduğu göze çarpmaktadır.

\section{Lisansüstü Tez Çalışmalarının Yıllara Göre Dağılımı}

İçerik analizi yapılan tezlerin yıllara göre dağılımı Şekil 2'de gösterilmektedir.

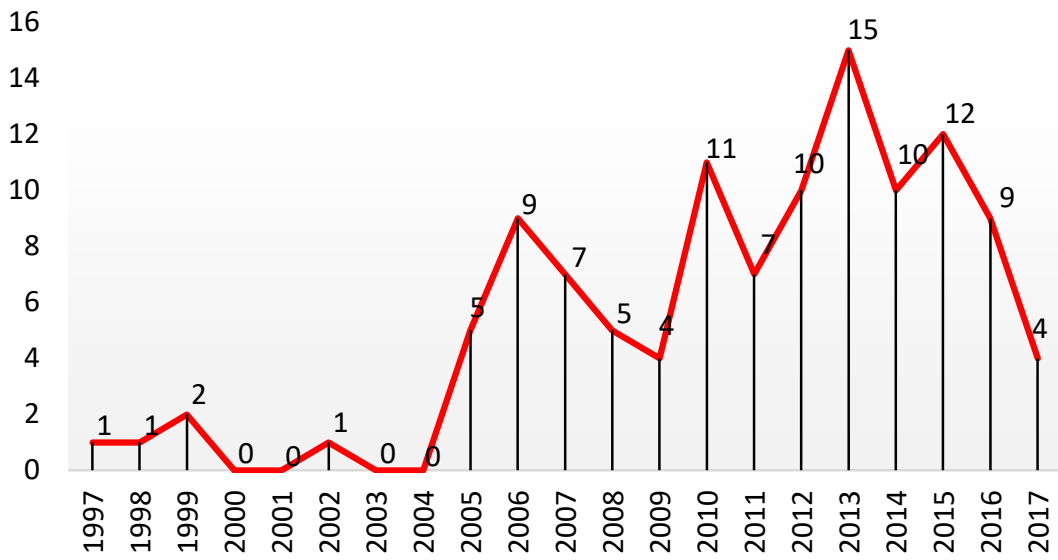

Şekil 2. Lisansüstü tez çalışmalarının yıllara göre dağılımı

Şekil 2'den tez sayısında yıllara göre belirli bir yönde eğilim olmadığı yani sürekli bir artış veya sürekli bir azalma göstermediği anlaşılmaktadır. Grafikte dalgalanma 
söz konusudur. 1997-2005 yılları arasında eğitsel oyuncak ve oyun içerikli toplam 5 lisansüstü tez çalışması yapılmışken, 2005 yılından sonra çalışmaların sayısının arttığı, 2013 yılının ise en fazla tez çalışmasının yapıldığg yıl olduğu görülmektedir. 2000, 2001, 2003 ve 2004 yıllarında ise eğitsel oyuncak ve oyun içerikli hiç tez çalışmasının yapılmadığı, bu yıllar sonrasında 2009 ve 2017 yıllarında en az yapılan tez sayısının 4 olduğu ortaya konulmuştur.

\section{Lisansüstü Tez Çalışmalarının Yapıldıkları Üniversitelere Göre Dağılımı}

Tezlerin yapıldıkları üniversitelere göre dağılımı Tablo 1'de gösterilmektedir.

Tablo 1.

Lisansüstü Tez Çalışmalarının Yapıldıkları Üniversitelere Göre Dă̆ılımı

\begin{tabular}{lc}
\hline Üniversite & f \\
\hline Gazi Üniversitesi & 21 \\
Ankara Üniversitesi & 7 \\
Marmara Üniversitesi & 7 \\
Selçuk Üniversitesi & 7 \\
Çukurova Üniversitesi & 5 \\
Sakarya Üniversitesi & 4 \\
Dokuz Eylül Üniversitesi & 4 \\
Izzet Baysal Üniversitesi & 3 \\
Hacettepe Üniversitesi & 3 \\
Necmettin Erbakan Üniversitesi & 2 \\
Ondokuz Mayis Üniversitesi & 2 \\
Adnan Menderes Üniversitesi & 2 \\
Amasya Üniversitesi & 2 \\
Uludağ Üniversitesi & 2 \\
Karadeniz Teknik Üniversitesi & 2 \\
Inönü Üniversitesi & 2 \\
Niğde Üniversitesi & 2 \\
Onsekiz Mart Üniversitesi & 2 \\
Atatürk Üniversitesi & 2 \\
Kocatepe Üniversitesi & 2 \\
Celal Bayar Üniversitesi & 2 \\
Muğla Üniversitesi & 2 \\
Yeditepe Üniversitesi & 2 \\
Frat Üniversitesi & 2 \\
Gazi Osman Paşa Üniversitesi & 2 \\
Kafkas Üniversitesi & 2 \\
Adiyaman Üniversitesi & 2 \\
Süleyman Demirel Üniversitesi & 2 \\
Ahi Evran Üniversitesi & 2 \\
Sütçü İmam Üniversitesi & 1 \\
Karabük Üniversitesi & 1 \\
Erciyes Üniversitesi & 1 \\
& 2 \\
\hline
\end{tabular}


Istanbul Teknik Üniversitesi

Kırıkkale Üniversitesi

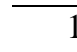

Trakya Üniversitesi

Bartın Üniversitesi

Fatih Üniversitesi

Pamukkale Üniversitesi

Bahçeşehir Üniversitesi

Başkent Üniversitesi

Anadolu Üniversitesi

Recep Tayyip Erdoğan Üniversitesi

Kocaeli Üniversitesi

Cumhuriyet Üniversitesi

Toplam

Tablo1 incelendiğinde, 112 lisansüstü tezden 21 tanesinin Gazi Üniversitesi’nde, her birinde yedi tane olmak üzere Ankara Üniversitesi-Marmara Üniversitesi ve Selçuk Üniversitesi'nde, beş tanesinin Çukurova Üniversitesi'nde, her birinde dört tane olmak üzere Sakarya Üniversitesi ve Dokuz Eylül Üniversitesi’nde yapıldığı görülmektedir. Diğer üniversitelerde ise bu konu içeriğiyle iki tane ya da bir tane lisansüstü tez çalışmasının yapıldığından bahsedilebilir. Buna göre, lisansüstü tezlerin üniversiteler arası dağılımında ilk sırayı Gazi Üniversitesi almaktadır.

\section{Lisansüstü Tez Çalışmalarının Anabilim Dallarına Göre Dağılımları}

Tez çalışmalarının anabilim dallarına göre dağılımları Şekil 3 'te gösterilmektedir.

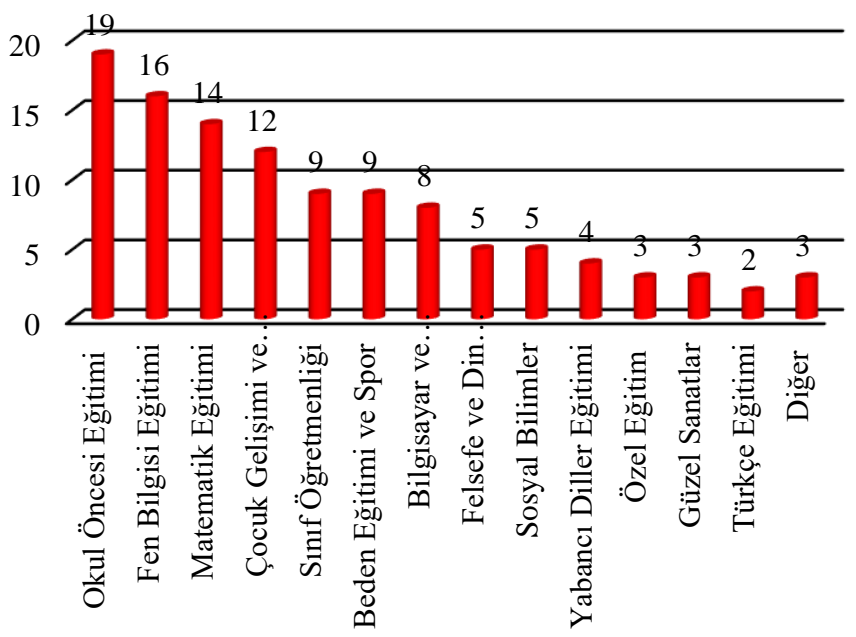

Şekil.3. Lisansüstü tez çalışmalarının anabilim dallarına göre dağılımları 
Şekil 3'e göre eğitsel oyuncak ve oyun alanında en çok lisansüstü tez çalışmasının Okul Öncesi Eğitimi Anabilim dalında (19) yapıldığı görülmektedir. Bu anabilim dalını; Fen Bilgisi Eğitimi (16), Matematik Eğitimi (14) ve Çocuk Gelişimi ve Eğitimi (12) anabilim dalları takip etmektedir. Eğitsel oyuncak ve eğitsel oyun alanında en az lisansüstü tez çalışmasının ise Türkçe Eğitimi Anabilim dalında (2) yapıldığı dikkat çekmektedir.

\section{Lisansüstü Tez Çalışmalarının Örneklem Büyüklüğü}

Tezlerde kullanılan örneklemlerin büyüklükleri Şekil 4’te gösterilmektedir.

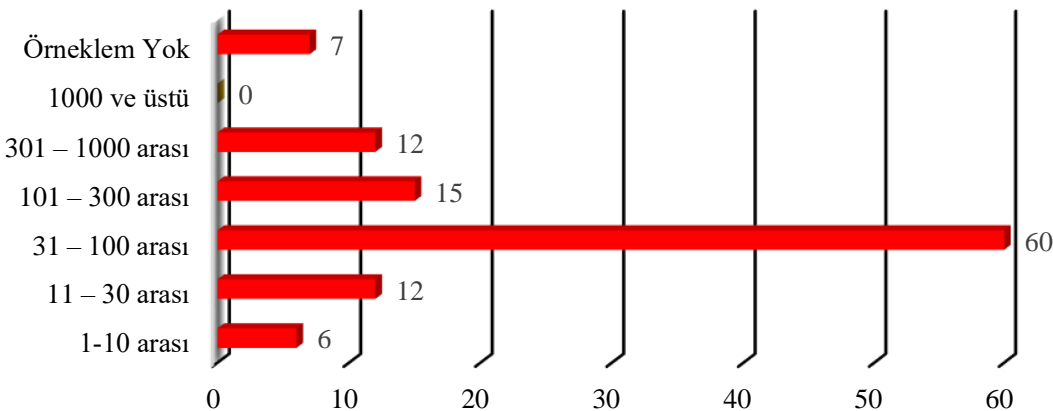

Şekil 4. Lisansüstü tez çalışmalarının örneklem büyüklüğü

Şekil 4'te eğitsel oyuncak ve oyun içerikli lisansüstü tez çalışmalarında en çok kullanılan örneklem büyüklüğünün 31 ile 100 arasında olduğu görülmektedir. Ayrıca altı çalışmada örneklem büyüklüğünün 10 veya 10'dan küçük, 12 çalışmada 11 ile 30 arasında, 60 çalışmada 31 ile 100 arasında, 14 çalışmada 301 ile 1000 arasında olduğu görülmektedir. Örneklem büyüklüğünün 1000'in üzerinde olduğu bir çalışma ise bulunmamaktadır. Bu durum eğitsel oyuncak ve oyun içerikli çalışmalarda daha çok 31-100 kişi aralığında çalışma gruplarının tercih edildiğini göstermektedir.

\section{Lisansüstü Tez Çalışmalarında Kullanılan Örneklem Düzeyleri}

Tezlerde çalışılan örneklemlerin düzeyleri Tablo 2'de gösterilmektedir.

Tablo 2.

Lisansüstü Tez Çalışmalarının Örneklem Düzeyi

\begin{tabular}{lrr}
\hline & f & \% \\
\hline Ortaokul & 46 & 41.1 \\
Okul Öncesi & 23 & 20.6 \\
İlkokul & 12 & 10.6 \\
Öğretmen & 9 & 8 \\
Veli & 7 & 6.2 \\
Özel Eğitim & 4 & 3.6
\end{tabular}




\begin{tabular}{lll} 
Üniversite Öğrencisi & 2 & 1.8 \\
Lise & 2 & 1.8 \\
Örneklem yok/ Belirtilmemiş & 7 & 6.2 \\
\hline
\end{tabular}

Tablo 2'ye göre eğitsel oyuncak ve oyun içerikli lisansüstü tez çalışmalarında en çok ortaokul $(5,6,7 \mathrm{ve} 8$. Sınıf) düzeyinde öğrencilerden oluşan çalışma gruplarından yararlanıldı̆̆ görülmektedir. $46(\% 41.1)$ tez çalışmasında ortaokul düzeyinde öğrencilerden yararlanılmıştır. İkinci sırada 23 (\%20.6) tez çalışması ile okul öncesi öğrencileri ve sonrasında $12(\% 10.6)$ tez çalı̧̧ması ile ilkokul öğrencileri gelmektedir. Taranan araştırmalarda ortaöğretim ve yükseköğretim düzeyinde sıklıkla çalışılmadığı, öğretmen ve veliler ile yapılan çalışmaların sınırlı sayıda olduğu görülmektedir. Yedi (\%6.2) tezde ise örneklem sayısının belirtilmediği görülmektedir.

\section{Lisansüstü Tez Çalışmalarında Kullanılan Değişkenler}

İçerik analizi yapılan 112 lisansüstü tez çalışmasında kullanılan değişkenler Tablo 3 'te gösterilmektedir.

Tablo 3.

Lisansüstü Tez Çalışmalarında Kullanılan Değişkenler**

\begin{tabular}{lcc}
\hline & f & \% \\
\hline Öğrenme Düzeyine Etkisi-Başarı & 49 & 30.1 \\
Gelişim Düzeyi Üzerine Etkisi & 29 & 17.8 \\
Tutum & 18 & 11.1 \\
Kalıcılık & 18 & 11.1 \\
Öğrencilerin Oyun Algısı & 11 & 6.7 \\
Oyun Yönteminin Uygulanma Düzeyi & 7 & 4.3 \\
Eğitsel Oyun-Oyuncakların Önemi & 6 & 3.7 \\
Eğitsel Oyun ve Oyuncak Araştırma-Geliştirme & 6 & 3.7 \\
Öğretmenlerin Yeterlilik Düzeyi & 5 & 3.1 \\
Öğrencilerin Oyun ve Oyuncak Tercihi & 3 & 1.8 \\
Motivasyon & 3 & 1.8 \\
Eğitsel Oyuncak ve Oyun Ebeveyn Görüşüu & 2 & 1.2 \\
Oyun Bağımlılığ1 ve Değişkenleri & 2 & 1.2 \\
Oyun Materyali İncelenmesi & 1 & 0.6 \\
Eğitsel Oyuncak ve Oyun Öğretmen Görüşü & 1 & 0.6 \\
Diğer & 2 & 1.2 \\
\hline Toplam & 163 & 100 \\
\hline
\end{tabular}

* Birden fazla seçenek işaretlenmiştir

Tablo 3 incelendiğinde eğitsel oyuncak ve oyun içerikli lisansüstü tez çalışmalarında en çok kullanılan değişken 49 (\%30.1) çalışma ile başarı değişkenidir. Bu değişkeni 29 (\%17.8) çalışma ile eğitsel oyun ve oyuncaklar ile yapılan eğitim ve öğretimin öğrencilerin gelişim düzeyi üzerine etkisi ve 18 (\%11.1) çalışma ile yine eğitsel oyun ve oyuncaklar ile yapılan eğitim ve öğretimin öğrencilerin derse karşı olan tutumları ve edinilen bilgilerin kalıcılı̆̆ı değiş̧eni takip etmektedir. 14 farklı 
değişken kullanılarak farklı araştırmalar yapılmıştır. İçerik analizi yapılan tez sayısı 112 olmasına rağmen kullanılan değişken sayısı 163 olarak belirlenmiştir.

\section{Lisansüstü Tez Çalışmalarının Yöntemleri}

Tezlerde kullanılan yöntemlerin dağılımı Şekil 5'te gösterilmektedir.

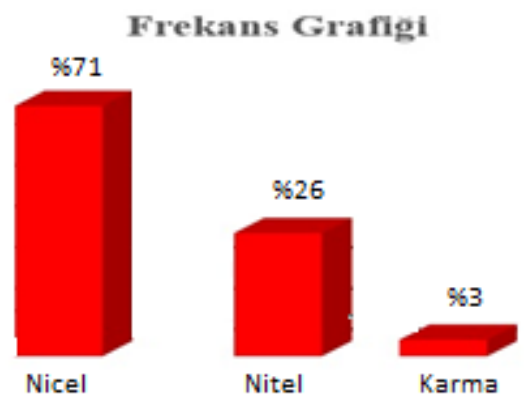

Şekil 5. Lisansüstü tez çalışmalarının yöntemleri frekans ve yüzde dağılımı

Şekil 5 incelendiğinde eğitsel oyuncak ve oyun içerikli yapılan lisansüstü tez çalışmalarında \%71 ile en çok nicel araştırma deseni (79), daha sonra sıra ile \%26 ile nitel (30) ve \%3 ile en az karma (4) yönteminin kullanıldığg belirlenmiştir. Bu durum eğitsel oyuncak ve oyun ile ilgili lisansüstü tez çalışmalarında nicel araştırma yönteminin baskın olarak tercih edildiğini göstermektedir.

\section{Lisansüstü Tez Çalışmalarında Kullanılan Veri Toplama Teknik ve Araçları}

Tezlerde kullanılan veri toplama teknik ve araçları Tablo 7'de sunulmaktadır. Tablo 4.

Lisansüstü Tez Çalışmalarında Kullanılan Veri Toplama Teknik ve Araçları*

\begin{tabular}{lcc}
\hline & f & \% \\
\hline Bäsarı Testi & 52 & 27.5 \\
Ölçek & 45 & 23.8 \\
Kişisel Bilgi Formu & 27 & 14.3 \\
Gözlem & 16 & 8.5 \\
Görüşme formu & 15 & 7.9 \\
Anket & 14 & 7.4 \\
Doküman İnceleme & 12 & 6.3 \\
Diğer & 38 & 20.1 \\
\hline
\end{tabular}

\footnotetext{
* Birden fazla seçenek işaretlenmiştir
}

Tablo 4 incelendiğinde en çok kullanılan veri toplama tekniğinin \%27.5 ile başarı testinin olduğu görülmektedir. Başarı testini; \%14.3 ile kişisel bilgi formu, \%8.5 ile gözlem, \%7.9 ile görüşme formu ve \%6.3 ile doküman inceleme yer almaktadır.\%7.4 ile anket kategorisi içinde genellikle araştırmacı tarafından oluşturulmuş, çalışma grubundan görüş almak için kullanılmış veri toplama araçları yer almaktadır. $\% 23.8$ 
oran alan ölçek kategorisi içinde tutum ölçekleri, alg1 ölçekleri, hazırbulunuşluk ölçekleri, motivasyon ölçekleri gibi geçerlilik ve güvenilirlik çalışmaları yapılmış ve herhangi bir özelliği ölçmeye yarayan ölçme araçları gruplanmıştır. Tabloda \%20.1 oranlı diğer kategorisinde ise çalışmada kullanılan araştırmacı günlüğü, kontrol listesi, değerlendirme formu, günlükler, sınıflama formu, kullanılabilirlik ve kalıcılık testleri gibi veri toplama araçları yer almaktadır. İçerik analizi yapılan tez sayısı 112 olmasına rağmen kullanılan veri toplama teknik ve araç sayısı 219 olarak belirlenmiştir.

\section{Lisansüstü Tez Çalışmalarında Kullanılan Nicel ve Nitel Veri Analizleri}

Tezlerde kullanılan nicel ve nitel veri analizleri Şekil 6'da sunulmaktadır.

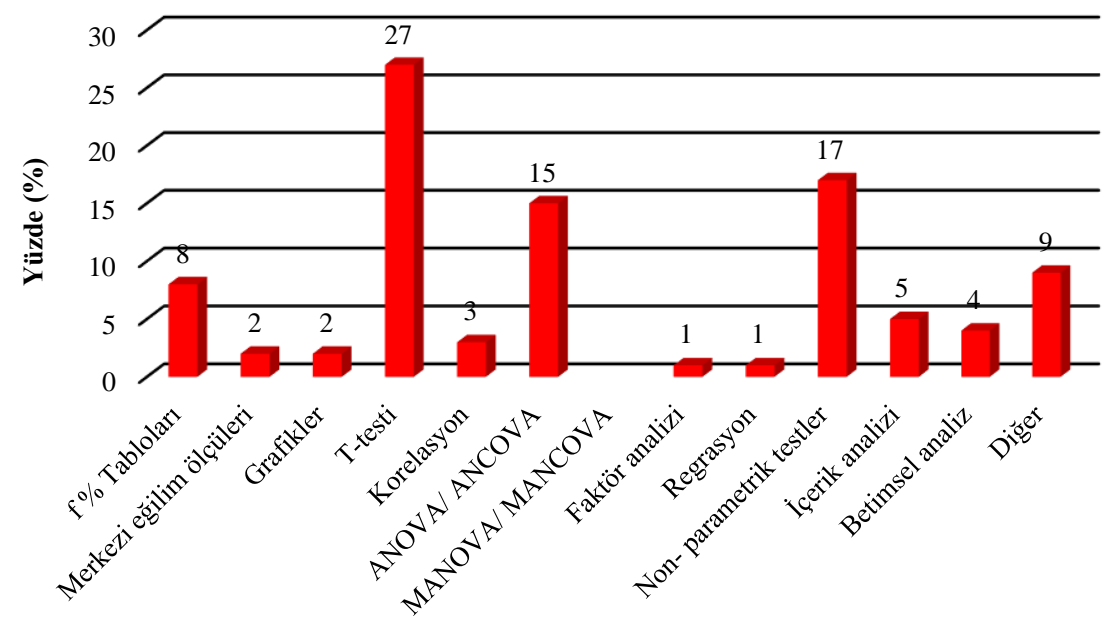

Şekil 6. Lisansüstü tez çalışmalarında kullanılan nicel ve nitel veri analizleri

Şekil 6 incelendiğinde araştırmacıların lisansüstü tez çalışmalarında nicel kestirimsel istatistik yöntemleri içerisinden t-testi (\%27), non-parametrik testler (\%17) ile ANOVA/ANCOVA testlerini (\%15), nicel betimsel istatistik yöntemleri içerisinden $\mathrm{f}-\%$ tablolarını $(\% 8)$ ve merkezi eğilim ölçülerini (\%2), nitel veri analiz yöntemleri içerisinden ise içerik analiz yöntemini (\%5) yüksek oranda kullandıkları görülebilmektedir.

Taranan tezlerde t-testinden $\% 27$ oranında yararlanıldığı görülmüştür. T-testi bağımsız değişkenlerin bağımlı değiş̧ken üzerindeki etkisini araştırmak başka bir deyişle iki grubun ortalamalarını karşılaştırıp aradaki farkın hangi yönden anlamlı olduğuna karar vermek amacıyla yapılan bir veri analizi çeşididir.

Araştırmalarda kullanılan bir başka analiz şekli ise Non-parametrik testlerdir. Non-parametrik testler nicel bir analiz şekli olup verilerin kategorik, örnek hacminin küçük, uygulanmasının ve anlaşılmasının kolay olduğu durumlarda yol göstericidir. 
Taranan tezlerde Non-parametrik test türlerinden en çok; birbirinden bağımsız iki grubun medyan (ortanca) değerlerini karşılaştırıp aralarında anlamlı bir farklılık gösterip göstermediğini denemek amacıyla uygulanan Mann Whitney U Testi ile araştırmaya konu örneklem iki durumda ya da iki farklı koşulda ölçümün yapıldığı Wilcoxon İşaretli Sıralar Testi kullanıldığı görülmüştür.

\section{Tartışma, Sonuç ve Öneriler}

Bu çalışmada, Türkiye'de eğitsel oyuncak ve eğitsel oyunların araştırmasını yapan, eğitsel oyuncak ve oyunların türlerini belirleyen, eğitim-öğretim sürecinde etkililiğini test eden bilimsel araştırma tezleri çeşitli açılardan incelemiştir. İncelemeler yapılırken toplam on araştırma sorusuna cevap bulmak hedeflenmiştir. Bu bölümde bütün araştırma sorularına yönelik bulgular birer birer ele alınmış, ulaşılan sonuçlar bu başlık altında tartışılmıştır.

Şekil 1 incelendiğinde çalışmaya dahil edilen 112 tezden 97'sinin yüksek lisans tezi olduğu görülmektedir. 1997 yılından günümüze kadar olan süreçte yazılmış olan yüksek lisans tezi sayısının doktora tezi sayısından 4 kattan fazla olması dikkat çekicidir. Yüzde oranının bu kadar yüksek çıkması bu konunun yüksek lisans düzeyinde daha fazla ilgi gördüğünü söylemeyi mümkün kılmaktadır. Bu durumun, üniversitelerin yüksek lisans kontenjanlarının genellikle doktoraya göre daha fazla olması ve doktorada eğitim süresinin yüksek lisansa kıyasla daha uzun olması gibi birtakım faktörlerden de kaynaklandığını ifade etmek mümkün olabilir.

Şekil 2 incelendiğinde yıllara göre dağılım yapılan tez sayısında belirgin bir eğilime rastlanmamakta dalgalanma olduğu görülmektedir. 2010-2016 yılları arasında yapılan tezlerin sayıca oranı diğer yıllara göre daha fazladır. 2000, 2001, 2003 ve 2004 yıllarında eğitsel oyuncak ve oyun ile ilgili hiç tez çalışmasının yapılmadığı, 2013 yılının ise 15 tez ile en fazla tez çalışmasının yapıldığı yıl olduğu anlaşılmaktadır. Bu durum ülkemizde 2010 yılından itibaren oyun ve oyuncağa yönelik çalışmaların yapıldığını göstermektedir.

Tablo 2 incelendiğinde 112 lisansüstü tezinin 21 tanesinin Gazi Üniversitesi’nde yapıldığg, taranan içerikte araştırma yapıp tez hazırlayan üniversite sayısının ise 44 olduğu görülmektedir. Türkiye'de özel üniversiteler ile birlikte 185 üniversite olduğu bilindiğine göre araştırılan içeriğin Türkiye'deki her üniversite tarafından tercih edilmediği anlaşılmaktadır.

Şekil 3'e göre eğitsel oyuncak ve oyun alanında en çok lisansüstü tez çalışmasının Okul Öncesi Eğitimi Anabilim Dalında (19) yapıldığı görülmektedir. Bu bulguda 5-7 yaş aralığındaki çocuğun hala oyun evresinde olması, eğitim ve öğretimde daha çok oyuncak materyallerinden ve çocukların bedensel ve ruhsal gelişimine katkı sağlayacak oyunlardan yararlanılması sebep olarak gösterilebilir. 5-7 yaş grubu eğitimi okul öncesi döneme rastlandığı için Okul Öncesi Anabilim Dalında bu konuda daha çok bilimsel lisansüstü tez çalışması yapılması uygun bulunabilmektedir. Şekil 
3'e göre bu anabilim dalını Fen Bilgisi Eğitimi (16) ve Matematik Eğitimi (14) takip etmektedir. Bu bulguya dayanarak artık eğitsel oyuncak ve oyunların derslere uyarlandığı akademik başarıyı artırmak için derslerde kullanılabilecek bir materyal ve yöntem olarak karşımıza çıktığını tahmin edebiliriz.

Şekil 4 incelendiğinde eğitsel oyuncak ve oyun ile ilgili lisansüstü tez çalışmalarında en çok kullanılan çalışma grubu büyüklüğünün 31 (\%53.5) ile 100 arasında (\%60) olduğu görülmekte diğer taraftan taranan tezler arasında 1000 ve üstü örneklem hacmine sahip hiçbir teze rastlanılmamıştır. Bu sık kullanılan ya da hiç kullanılmayan örneklem aralıkları Erdoğmuş'un (2009) da araştırmalarında belirttiği gibi uygulama yapmak için ayrılmış olan sınırlı zaman aralığından, etik olması gereken resmi süreçlerden, araştırmacıların kısa sürede daha kolay bir yollardan veriye ulaşmayı hedeflemelerinden kaynaklanabilmektedir. 7 tez çalışmasında örneklem sayısının belirtilmediği görülmektedir. Bu bulgu ise 7 tezde herhangi bir örneklem grubuyla çalışılmadığı sonucunu ortaya çıkarmıştır.

Tablo 2 incelendiğinde eğitsel oyuncak ve oyun ile ilgili lisansüstü tez çalışmalarında en çok ortaokul $46(\% 41.1)$ yani $5,6,7$ ve 8 . sinıf düzeyinde öğrencilerden oluşan çalışma gruplarından yararlanıldığ görülmektedir. En fazla lisansüstü tez çalışması Okul Öncesi Anabilim Dalında yapılmış olsa da tezlerde çalışma grubu olarak kullanılan okul öncesi örneklemi 23 (\%20.6) tez ileile ikinci sırada yer almaktadır. Diğer anabilim dallarının toplam frekansı Okul Öncesi Anabilim Dalı frekansından yüksek olduğu için bu sonucun ortaya çıktığ 1 düşünülebilir. Çalışmaların ortaöğretim ve yükseköğretim düzeyinde sıklıkla yürütülmediği, örneklem düzeyi olarak en az öğretmen ve velilerin seçildiği anlaşılmaktadır. Bu bulguda, verilere ulaşmak için öğrenciler ile yapılması planlanan çalışmaların daha kolay, daha rahat ve daha kolay ulaşılabilir olması sebep gösterilebilir.

Tablo 3 incelendiğinde eğitsel oyuncak ve oyun ile ilgili lisansüstü tez çalışmalarında en çok kullanılan değişken \%30.1 ile başarı değişkenidir. Bu değişkeni \%17.8 ile eğitsel oyun ve oyuncaklar ile yapılan eğitim ve öğretimin öğrencilerin gelişim düzeyi üzerine etkisi, \%11.1 ile öğrencilerin derse karşı olan tutumları ve edinilen bilgilerin kalıcılığı değişkeni takip etmektedir. Bu bulgu artık eğitsel oyun ve oyuncakların derslere harmanlandığını, derslerde kullanılan bir yöntem olduğunu açığa çıkarmaktadır. İçerik analizi yapılan tez sayısı 112 olmasına rağmen kullanılan değişken sayısı 163 olarak belirlenmiştir. Bu durum eğitsel oyuncak ve oyun ile ilgili bazı tez çalışmalarında birkaç değişken üzerinden araştırma yapıldığını göstermektedir. 14 farklı değişken kullanılarak araştırmaların yapılması ise taranan tez çalışmalarında hep aynı değişken üzerinden araştırma yapılmadığını farklı değişkenlerin tercih edildiği bilgisini bize sunmaktadır.

Şekil 5 incelendiğinde eğitsel oyuncak ve oyun içerikli yapılan lisansüstü tez çalışmalarında ile en çok nicel yöntemin (\%71) kullanıldığı, bu yöntemi azalan oranla nitel (\%26) ve karma modeli (\%3 18) yöntemlerinin izlediği görülmektedir. 
Çalışmada nicel, nitel ve karma yöntemleriyle taranan araştırmaların daha yüksek oranda tam-yarı deneysel, tarama, açıklayıcı ve alanyazın derleme araştırma desenleriyle incelendiği saptanmıştır. Alanyazında da bu sonuçlara ulaşmış araştırmalara ulaşmak olasıdır (Gülbahar ve Alper, 2009; Gül ve Sözbilir, 2016; Hew, Kale ve Kim, 2007; Hranstinski ve Keller, 2007; Ross, Morrison ve Lowther, 2010; Ulutaş ve Ubuz, 2008). Bu durumun nedeni, çalışmalarda iç geçerlilik oranını yükseltmek için tam-yarı deneysel araştırma desenlerinin ön planda tutulması olabilmektedir (Slavin, 2008). Nicel araştırmaların, kapsamlı örneklem gruplarına ulaşabilme, sonuçları genelleyebilme, zaman ve maliyet açısından olumlu özellikler barındırması araştırmacılar tarafından daha fazla oranda benimsenmesine sebep olmuş olabilir (Göktaş vd., 2012a). Karma araştırma yöntemi ise çalışmalarda çok tercih edilmeyen yöntem olarak belirlenmiştir. Taranan tezlerde karma araştırma deseninin daha az kullanılan bir yöntem olarak seçilmesinin sebebi ise bu yöntemin son yıllarda popüler olup yeni kullanılmaya başlanması ve dolaylı olarak araştırmacıların karma araştırma yöntemine dair bilgi ve beceriye sahip olamamaları ile yönteme karşı geliştirdikleri olumsuz tutumları olabilir. Benzer bulgulara ulaşan birçok araştırma da bulunmaktadır (Chang, Chang ve Tseng, 2010; Lee, Wu ve Tsai, 2009).

Tablo 4 incelendiğinde en çok kullanılan veri toplama tekniğinin \%27.5 ile başarı testinin olduğu görülmektedir. Başarı testini; \%14.3 ile kişisel bilgi formu ,\%8.5 ile gözlem, \%7.9 ile görüşme formu ve \%6.3 ile alanyazın taraması yer almaktadır. Başarı testleri oranın yüksek çıkması taranan çalışmalarda nicel yöntemde deneysel araştırma deseninin kullanılmasının sonucu olabilir. Başarı testleri güvenilir olduğu ve denk olduğu hedef davranışlar bakımından eğitim-öğretimin her aşamasında kullanılabilecek bir veri toplama aracıdır. Aynı zamanda öğrencilerin bilişsel, duyuşsal ve devinişsel kazanımlar bakımından hazırbulunuşluk seviyelerini belirlemekte, başarılı olamayan öğrencilerin öğrenme eksiklerini gidermekte, öğretim etkinlikleriyle kazandırılması planlanan eğitim amaçlarına ulaşılabilme seviyesi hakkında bir yargıya varmak için tasarlanmış bir materyaldir. Başarı testlerinden geniş bir yelpazede veri elde edilebilmesi, elde edilen verilerin ulaşılabilir sayısal değerlerine uygun programlar kullanılarak kolayca hesaplanabilmesi başarı testi kullanım yüzde oranının yüksek olmasına sebep olabilir. İçerik analizi yapılan tez sayısı 112 olmasına rağmen kullanılan veri toplama teknik ve araç sayısı 219 olarak belirlenmiştir. Bu durum eğitsel oyuncak ve oyun içerikli doküman analizi yapılan tez çalışmalarında hep aynı veri toplama teknik ve araç ile araştırma yapılmadığını, farklı teknik ve araçların tercih edildiğini, bazı tezlerde ise birkaç veri toplama teknik ve araç ile araştırma yapıldığını göstermektedir. Araştırma sonucu ulaşılan bulgularda güvenilirlik düzeyini yükseltmek ve daha doğru ve kapsamlı sonuçlara varabilmek için tek bir veri toplama aracı ile sınırlı kalmamak araştırmacılardan istenilen bir durumdur. Bu sayede geçerliği ve güvenirliği yüksek olan kaliteli çalışmalar yapılması sağlanacaktır. 
Şekil 6 incelendiğinde araştırmacıların lisansüstü tez çalışmalarında nicel kestirimsel istatistik yöntemleri içerisinden t-testi (\%27), non-parametrik testler (\%17) ile ANOVA/ANCOVA testlerini (\%15), nicel betimsel istatistik yöntemleri içerisinden $\mathrm{f}-\%$ tablolarını $(\% 8)$ ve merkezi eğilim ölçülerini $(\% 2)$, nitel veri analiz yöntemleri içerisinden ise içerik analiz yöntemini (\%5) yüksek oranda kullandıkları görülebilmektedir. Arık ve Türkmen (2009) ve Erdem (2011) de araştırmalarda en sık frekans- yüzde değerleri, ANOVA ve betimsel istatistiklerin kullanıldığını belirlemiştir. $\mathrm{Bu}$ bulgulardan yola çıkarak çalışılan tezlerde de benzer sıralamanın olduğu, çok değişkenli analizlerin kullanım oranının düşük olduğu, deneysel çalışmalar ANCOVA kullanmayı gerektirse de t-testinin tercih edildiğini ya da araştırmacılar tarafından daha çok bu analiz türlerinin bilindiği için bunların kullanıldığı gibi sonuçlara varılabilir.

Ulaşılmış olan bulguların değerlendirilmesi kapsamlı olarak yapıldığında bu çalışma ile eğitsel oyuncak ve eğitsel oyun içerikli araştırmalardaki genel ve güncel yönelimler belirlenmiştir. Bununla birlikte araştırmacıların daha çok hangi konulara daha çok eğilim gösterdikleri, hangi tür veri toplama araçları kullanarak nasıl örneklem gruplarıyla yüksek oranda çalışmalarını yürüttüklerini, ne tür araştırma ve veri analiz yöntemlerinden yana seçimlerini yaptıkları ortaya konulmuştur.

Araştırma gösteriyor ki; Türkiye'de eğitsel oyuncak ve oyun içerikli bilimsel araştırma tezlerinin çoğu yükseklisans tezidir. Yıllara göre dağılıma bakıldığında belirgin bir eğilime rastlanmamış en fazla 2013 yılında 15 çalışma yapıllmıştır. Anabilimdalı olarak daha çok Okul Öncesi Anabilim Dalı, bu içerikte en çok araştırma yapan üniversite ise Gazi Üniversitesidir. En çok kullanılan çalışma grubu düzeyi ortaokul olup büyüklüğü 31 ile 100 arasındadır. Taranan çalışmaların bir kısmında örneklem grubuyla çalışılmamıştır. Bu çalışmalarda oyun ve oyuncağın ne olduğu, tarihsel gelişim süreçleri, bu süreçte nasıl çeşitlendiği, eğitim-öğretim sürecinde geçmişten günümüze kullanılan örnekleri, çocukların cinsiyete bağlı oynadıkları oyun ve oyuncak türleri, çeşitli derslerdeki uygulamaları, bireyin gelişimine olan etkileri, kullanım alanları, oyun kuramları, bazı düşünürlerin görüşleri, müfredattaki yeri ve önemine yer verilmiştir. Değişken olarak başarı ön planda tutulmakta veri toplama tekniği olarak daha çok başarı testi uygulanmaktadır. Nicel araştırma yöntemi büyük ölçüde tercih edilmekte olup nicel kestirimsel istatistik yöntemlerinden t-testi, nonparametrik testler ile ANOVA/ANCOVA testleri nitel veri analiz yöntemlerinden ise içerik analiz yöntemini kullandıkları ortaya çıkmıştır.

Çalışmadan elde edilen sonuçların ilgili alanda araştırma yapacak ya da yapmakta olan araştırmacılara yeni bakış açıları kazandırabileceği, yaptıkları çalışmaların güçlü ve eksik noktalarını belirleme açısından faydalı olabileceği, gelecekte yapılacak olan çalışmalara yol göstermede tanımlayıcı bir kaynak olabileceği ve ilgili alanın araştırma ihtiyaçlarının belirlenmesi konusunda da katkı sağlayacağı düşünülmektedir. 
Çalışma sonuçlarının 1997-2017 yılları arasındaki YÖK Ulusal Tez Merkezinde Türkçe dilinde yapılan alan yazın taraması sonucu ulaşılabilen araştırmalarla sınırlı olduğu unutulmamalıdır. Bu doğrultuda gelecek çalışmalarda aynı anahtar kelimeler kullanılarak yabancı dillerde yayınlanmış uluslararası tezlerde ya da makalelerde içerik analizi yapılarak daha geniş bir tablo çizilebilir.

Araştırmalarda ulaşılan örneklem sayılarının büyütüldüğü, yöntem ile süreçteki uygulama etkinliklerinin zenginleştirildiği, olumlu hipotezler kurarak amaca uygun olan nitelikli uygulamaların yapılması desteklenmelidir. Veri analizinin yapılabilmesi için kullanılacak yöntem ve araştırma desenlerinin çeşitlendirilmesi, araştırmacıların analiz sürecine dahil olup yöntemleri olabildiğince iyi kullanması sağlanmalıdır. Bu amaçla lisansüstü düzeyde ve üstünde okutulan araştırma yöntemleri ve istatistik dersleri daha etkin ve kapsamlı olmalıdır. İçerik analizi çalışmaları günler belki de aylar süren her zaman dikkatli olup mütemadiyen çalışmayı gerektiren bir süreç sonunda şekillenebilmektedir. Araştırmacıların bu süreci daha rahat geçirebilmeleri için araştırmanın en başında itinayla çalışıp plan yapmaları önerilmektedir.

\section{Kaynakça}

Altun, E. (2009). Özel öğretim yöntemleri. Ankara: Pegem Yayınevi.

Altunay, D. (2004). Oyunla desteklenmiş matematik öğretiminin öğrenci erişisine ve kalıcılı̆̆a etkisi (Yayımlanmamış yüksek lisans tezi). Gazi Üniversitesi, Ankara.

Arık, R.S. \& Türkmen, M. (2009, Mayıs). Eğitim bilimleri alanında yayımlanan bilimsel dergilerde yer alan makalelerin incelenmesi. I. Uluslararası Türkiye Eğitim Araştırmaları Kongresi'nde sunulan sözel bildiri, Çanakkale.

Baykoç Dönmez, N. (1992). Çocuğun sosyal ve duygusal gelişiminde oyunun rolü. Okul Öncesi Dergisi, 43, 10-12.

Bilen, M. (2002). Plandan uygulamaya öğretim. Ankara: Anı Yayıncılık.

Chang, Y.H., Chang, C.Y. \& Tseng, Y.H. (2010). Trends of science education research: an automatic content analysis. Journal of Science Education and Technology, 19(4), 315-331.

Cohen, L. \& Manion, L. (2001). Research methods in education. New York: Rotledge Falmer.

Çalık, M., Ünal, S., Coştu, B. \& Karataş, F.Ö. (2008). Trends in Turkish science education. Essays in Education, Special Edition, 23-45.

Çoşkun, H., Akarsu, B. \& Kariper, A. (2012). Bilim öyküleri içeren eğitsel oyunların fen ve teknoloji dersindeki öğrencilerin akademik başarılarına etkisi. Ahi Evran Üniversitesi Kırşehir Eğitim Fakültesi Dergisi, 13(1), 93-109.

Dağbaşı, G. (2007). Oyun tekniği ve arapça öğretiminde kullanımı (Yayımlanmamış yüksek lisans tezi). Gazi Üniversitesi, Ankara.

Demir, M. (2012). 7. Sinıf vücudumuzdaki sistemler ünitesinin oyun tabanlı öğrenme yaklaşımı ile işlenmesinin öğrencilerin akademik başarılarına ve fen teknoloji dersine karşı 
tutumlarına etkisi. X. Ulusal Fen ve Matematik Eğitimi Kongresi, Niğde Üniversitesi, Niğde.

Demirel, Ö. (1999). Planlamadan değerlendirmeye öğretme sanatı. Ankara: Pegem Akademi Yayınları.

Ekiz, D. (2009). Bilimsel araştırma yöntemleri. Ankara: Anı Yayıncılık.

Erdem, D. (2011). Türkiye'de 2005-2006 yılları arasında yayımlanan eğitim bilimleri dergilerindeki makalelerin bazı özellikler açısından incelenmesi: Betimsel bir analiz. Eğitimde ve Psikolojide Ölçme ve Değerlendirme Dergisi, 2(1), 140-147.

Erdoğmuş, F.U. (2009). Research trends in CEIT MS and PhD theses in Turkey: A content analysis (Master thesis). Middle East Technical University, Ankara.

Göktaş, Y., Hasançebi, F., Varısoğlu, B., Akcay, A., Bayrak, N., Baran, M. \& Sözbilir, M. (2012a). Trends in educational research in Turkey: A content analysis. Educational Sciences: Theory \& Practice, 12(1), 443-460.

Göktaş, Y., Küçük, S., Aydemir, M., Telli, E., Arpacık, Ö., Yıldırım, G. \& Reisoğlu, İ. (2012b). Türkiye'de eğitim teknolojileri araştırmalarındaki eğilimler: 2000-2009 dönemi makalelerinin içerik analizi. Kuram ve Uygulamada Eğitim Bilimleri, 12(1), 177-199.

Gül, Ş. \& Sözbilir, M. (2015). Fen ve matematik eğitimi alanında gerçekleştirilen ölçek geliştirme araştırmalarına yönelik tematik içerik analizi. Eğitim ve Bilim, 40(178), 85-102.

Gül, Ş. \& Sözbilir, M. (2016). International trends in biology education research from 1997 to 2014: A content analysis of papers in selected journals. Eurasia Journal of Mathematics, Science \& Technology Education, 12(6), 1631-1651.

Gülbahar, Y. \& Alper, A. (2009). Öğretim teknolojileri alanında yapılan araştırmalar konusunda bir içerik analizi. Ankara Üniversitesi Ĕ̈itim Bilimleri Fakültesi Dergisi, 42(2), 93-111.

Hançer, A.H. (2007). Fen eğitiminde yapılandırmacı yaklaşıma dayalı bilgisayar destekli öğrenmenin kavram yanılgıları üzerine etkisi. Cumhuriyet Üniversitesi Sosyal Bilimler Dergisi, 31(1), 69-81.

Hew, KF., Kale, U. \& Kim, N. (2007). Past research in instructional technology: Results of a content analysis of empirical studies published in three prominent instructional technology journals from the year 2000 through 2004. Journal of Educational Computing Research, 36(3), 269-300.

Hranstinski, S. \& Keller, C. (2007). An examination of research approaches that underlie research on educational technology: A review from 2000 to 2004. Journal of Educational Computing Research, 36(2), 175-190.

Kaptan, F. (1999). Fen bilgisi öğretimi. İstanbul: Milli Eğitim Basımevi.

Kirazoğlu, Z. (2000). Ünitelere göre hazırlanmış oyunlar. Bursa: Ezgi Kitapevi Yayınları.

Koçyiğit, S., Tuğluk, M.N. \& Kök, M. (2007). Çocuğun gelişim sürecinde eğitsel bir etkinlik olarak oyun. Atatürk Üniversitesi Kazım Karabekir Eğitim Fakültesi Dergisi, 16, 324-342. 
Lee, M.H., Wu, Y.T. \& Tsai, C.C. (2009). Research trends in science education from 2003 to 2007: A content analysis of publications in selected journals. International Journal of Science Education, 31(15), 1999-2020.

MEB. (2013). İlköğretim kurumları (ilkokullar ve ortaokullar) fen bilimleri dersi (3, 4, 5, 6, 7 ve 8 . Sınıflar) öğretim programı. Ankara: MEB Yayınevi.

Oktay, A. (2002). Yaşamın sihirli yılları: Okul öncesi dönem. İstanbul: Epsilon Yayınları.

Özkan, F. (2010). Illköğretim 6.sınıf web destekli fen ve teknoloji dersinde öğrencilerin bilgisayar öz-yeterlilik algıları, bilgisayara ve fene yönelik tutumları ve akademik başarıları (Yayınlanmamış yüksek lisans tezi). Ege Üniversitesi, İzmir.

Razon, N. (1984). Okul öncesi dönemde oyuncağın yeri ve önemi. Ya-Pa Okul Öncesi Eğitim Semineri, İstanbul.

Ross, S.M., Morrison, G.R. \& Lowther, D.L. (2010). Educational technology research past and present: Balancing rigor and relevance to impact school learning. Contemporary Educational Technology, 1(1), 17-35.

Selçuk, Z., Palanc1, M., Kandemir, M. \& Dündar, H. (2014). Eğitim ve bilim dergisinde yayınlanan araştırmaların eğilimleri: İçerik analizi. Eğitim ve Bilim, 39(173), 430-453.

Slavin, R. (2008). What works? Issues in synthesizing education program evaluations. Educational Researcher, 37(1), 5-14.

Sözbilir, M., Kutu, H. \& Yaşar, M.D. (2012). Science education research in Turkey: A content analysis of selected features of papers published. In J. Dillon \& D. Jorde (Eds), The World of Science Education: Handbook of Research in Europe (pp.341-374). Rotterdam: Sense Publishers.

Topsakal, Ü.U., Çalık, M. \& Çavuş, R. (2012). What trends do Turkish biology education studies indicate?. International Journal of Environmental and Science Education, 7(4), 639-649.

Tural, H. (2005). Illköğretim matematik ögretiminde oyun ve etkinliklerle öğretimin erişi ve tutuma etkisi (Yayınlanmamış yüksek lisans tezi). Dokuz Eylül Üniversitesi, İzmir.

Ulutaş, F. \& Ubuz, B. (2008). Research and trends in mathematics education: 2000 to 2006. Elementary Education Online, 7(3), 614-626.

Varışoğlu, B., Şeref, İ., Gedik, M. \& Yılmaz, İ. (2013). Türkçe dersinde uygulanan eğitsel oyunlara yönelik tutum ölçeği: geçerlilik ve güvenilirlik çalışması. Adıyaman Üniversitesi Sosyal Bilimler Enstitüsü Dergisi, 6(11), 1059-1080.

Vygotsky, L. (1986). Thought and language. Cambridge: MIT Press.

Yavuzer, H. (1984). Çocuk psikolojisi. İstanbul: Altın Kitaplar.

Yıldırım, A. \& Şimşek, H. (2005). Sosyal bilimlerde nitel araştırma yöntemleri. Ankara: Seçkin Yayınları.

Yıldırım, A. \& Şimşek, H. (2011). Sosyal bilimlerde nitel araştırma yöntemleri. Ankara: Seçkin Yayınları. 


\section{Extended Abstract}

In our knowledge era, the importance people give to the information, their desire to both benefit from the already existing information and to reach higher levels has been rising day by day. Trying to give an answer to this importance and desire, physical sciences are come up on existence as a lesson in education. Teachers are looking for new ways which are fun and interesting for students to take an active role in the education process. One of these methods which teachers can prefer and learners can take active roles in is using toys and games.

In the current education system, toys and games are used to, reinforce the learned concepts, provide recurrence in a more suitable and comfortable context, make the education and school environment more entertaining and remove the students' negative attitudes and bias against lessons. The only significant factor in games and toys is that it should be shaped and used in accordance with focused aims and objectives. A game and a toy are seen effective if they are, related with the achievements of the subject, suitable for students' age, gender and development characteristics and highly boosted in excitement, joy regarding students' likes \& dislikes.

It is highly important that;

- The lessons are carried out in a manner that students are active and the teacher is a guide

- The intended aims and objectives are easier to reach with the help of educational games and toys

- Improvement in the quality of education is provided and analysis of suitability for these determined describing criteria, evaluation in terms of integrity, are done for the maintenance of application and study works in this field.

To reveal the concentration of the studied works, which subjects and lessons they are in, via determining common tendencies and to prove the deficiencies in this field is the main objective of this study.

Questions below are tried to be answered within the scope of the study:

In postgraduate studies;

1. How does the statistical distribution change in terms of type?

2. How does the statistical distribution change in terms of time?

3. How the distribution is in universities?

4. How the distribution is with respect to the main study fields? 
5. How does the size of the sample / study groups change?

6. How does the level of the sample / study groups change?

7. What are the variables commonly used?

8. What are the methods/patterns of research commonly used?

9. What are the data collecting tools commonly used?

10. What are the data analysis methods commonly used?

With the help of this analysis and evaluation, a broader opinion about how much of the educational toys and games is reflected to our education system was obtained and it is thought that the kind of path it may follow in a 20 -year period can be revealed. The study will help the researchers, who are experienced or who find the usage of educational toys and games in education program beneficial, to catch up with the already done studies and it will be a guide for the future studies of the field.

In this study, studies were examined, which include any one or few of game-toyeducational key words that was executed in Turkey, which researches educational toys or games, which determines the types of the educational toys or games and which test the activity of these in the education process. With this aim, document review was done. Because of the abundance in the page numbers, document review was mostly done on articles instead of dissertations. From this perspective, the study presents significance. In a scan, started in 13 December 2017, about the keywords "game", "toy" and "educational game" in the Turkish Council of Higher Education National Thesis Centre, 112 dissertations were identified as being done in the years of 19972017. Thesis Classification Form was prepared via taking expert opinions. Content analysis in a descriptive way, which provide the combination of the results of the studies which resemble scientific research dissertations identified so far, was done. Microsoft Excel was used in the process of analysis.

According to the analysis results; $\% 86.6$ of the educational games and toys themed scientific dissertations are Masters' degree dissertations. It is highly noticeable that the number of Master's degree dissertations, which were written between 1997-2017, are 4 times higher than the number of Doctorate dissertations. When looked at the distribution through the time, one cannot see an explicit tendency towards the field which means there is not a sudden rise or decrease. The highest number of studies which were conducted on educational games and toys in a year can be seen in the year 2013 with a number of 15. The university which makes related studies is Gazi University, department of Preschool. Mostly used group of volunteers are secondary school students, the numbers change within the range of 31 to 100 . In some thesis (\%6.2 they do not work with sample groups. In these studies, it is worked on, what is a game or a toy, how it improved through history, how it diversified in this process, examples of it used in our education system, gender effect on the types of games and 
toys children play, applications in various lessons, its impact on individuals, usage areas, game theories, opinions of some philosophers, its importance on the curriculum. While for variables, success was held foreground, for data collection success tests were rather used. In the dissertations quantitative method (\%55) were used more than qualitative method (\%26) and Scanning Method (\%16). When looked at the data analysis methods, it can be seen that t-test from quantitative predictive statistic methods (\%27), non-parametric tests (\%17) and ANOVA/ANCOVA (\%15) were used. From qualitative research methods, content analysis (\%5) was rather used. It was determined that MANOVA/ MANCOVA statistical methods were never preferred.

It shouldn't be forgotten that these study results are limited to the literature review of the field covering the years 1997-2017 which was done in Turkish Council of Higher Education National Thesis Centre. In this direction, a broader table can be drawn by using the same keywords in the future studies or making content analysis on the studies done in other countries. It is thought that the results obtained from this study can, bring new perspectives, be beneficial in terms of determining the strong and weak sides of the studies, be a source of guide for the studies in the future and contribute to the determination of the needs of other studies. 